\title{
Detection of atrial septal defect with left-to-right shunt by inferior vena cava contrast echocardiography
}

\author{
GIUSEPPE GULLACE, MARIA TERESA SAVOIA, PIERFRANCO RAVIZZA, \\ MAURO KNIPPEL, CRISTIANO RANZI
}

From Divisione di Cardiologia, Ospedale di Circolo, Lecco CO, Italy

SUMMARY Contrast echocardiography was used before cardiac catheterisation in 37 patients with atrial septal defect and a left-to-right shunt and in 18 patients with a raised right atrial and ventricular pressure to assess the contrast echo effect in the inferior vena cava.

Using two dimensional contrast apical echocardiography we found a negative contrast echo effect within the right atrium in many but not all patients with atrial defect.

Contrast echoes entering the inferior vena cava during presystole or early to mid-diastole were detected in patients with heart disease causing raised right atrial and ventricular pressures and also in all patients with atrial septal defect. No contrast echo effect in the inferior vena cava was detected in 10 normal subjects. The sensitivity of this contrast pattern in the inferior vena cava in diagnosing atrial septal defect was $100 \%$. When other conditions causing raised right atrial pressure were excluded, the specificity and predictive accuracy were $100 \%$ for both.

The presystolic contrast echo effect in the inferior vena cava, semiquantitatively graded, correlated with the size of the shunt determined by oximetry.

In 20 patients re-examined after the surgical correction of the atrial septal defect, no presystolic contrast echo effect was detected in the inferior vena cava.

Contrast echocardiography of the inferior vena cava is a valuable and reliable method for diagnosing atrial septal defect with left-to-right shunt.

A dilated right ventricle and paradoxical interventricular septal motion, indicators of right ventricular volume overload, have been used as M-mode echocardiographic criteria for the diagnosis of atrial septal defect. ${ }^{1-4}$

Two dimensional echocardiography has improved the reliability of detection by the direct visualisation of the interatrial communication from the parasternal approach, ${ }^{45}$ the apical four-chamber view, ${ }^{6}$ and the subcostal view. ${ }^{78}$ Contrast echocardiography has also been used as a sensitive method for detecting rightto-left shunts ${ }^{910}$; but is usually considered of little value in patients with left-to-right shunts. ${ }^{9}$ Recent investigations, however, have improved its reliability in the latter. ${ }^{1-13}$

The subcostal approach has made it possible to detect contrast echoes entering the inferior vena cava during presystole in patients with an atrial septal defect and a left-to-right shunt and in patients with

Accepted for publication 16 October 1981 raised right atrial and ventricular pressure, using the contrast echo technique. ${ }^{14-16}$

The present investigation aimed to test the sensitivity, specificity, and predictive accuracy of presystolic contrast echoes entering the inferior vena cava in patients with atrial septal defect and a left-to-right shunt, comparing them with a group having raised right atrial and right ventricular pressures, and a group of normal subjects.

\section{Patients and methods}

We examined 40 consecutive patients (mean age $28 \pm 13$; range 7 to 54 years) who presented with a clinically suspected atrial septal defect with left-toright shunt and sinus rhythm. Thirty-seven patients were included in the present study because, from the two dimensional echocardiographic subcostal approach, they showed a dropout of echoes at the level of the interatrial septum, indicating an atrial septal defect. ${ }^{7}$ Three patients were excluded because 
the septum appeared intact. Eighteen patients (mean age $36 \pm 8$ ) with high right atrial and ventricular pressures (eight with pericardial effusion, seven with congestive cardiomyopathy, one with pulmonary stenosis, and two with pulmonary hypertension caused by mitral stenosis, all diagnosed by routine echocardiography) were also studied. Ten normal subjects constituted a third group; all gave informed consent after full explanation.

All patients underwent cardiac catheterisation one to three days after contrast echocardiography. The criteria used to diagnose an atrial septal defect were the presence of a left-to-right shunt on oximetry, the passage of the catheter from the right to the left atrium, and the detection of a jet of contrast passing from the left to the right atrium when the pulmonary angiogram was reviewed in slow motion. We reexamined 20 of the patients with atrial septal defect one to 10 months after its surgical correction.

\section{CONTRAST ECHOCARDIOGRAPHY}

Peripheral (left or right antecubital vein) injections of $10 \mathrm{ml} 5 \%$ glucose solution were given to all patients and normal subjects. A butterfly needle of $1.1 \mathrm{~mm}$ in diameter was used. The first injection was intended to test the occurrence of contrast echoes during the two dimensional examination. All subsequent injections in each patient were given by the same operator using the same force, sufficient to obtain a contrast echo effect in the right atrium. All patients and normal subjects were asked to breathe normally during each injection. The echocardiographic approaches used during contrast-producing injections were the two dimensional apical four-chamber views and two dimensional and $M$-mode subcostal views. One or two injections were given for each view. All contrast injections were continuously recorded without changing the transducer position or gain control during either the two dimensional or M-mode examination.

\section{ECHOCARDIOGRAPHY}

A commercially available phased array sector scanner IREX System III and a mechanical sector scanner Aloka SSD $110 \mathrm{~S}, 2.25 \mathrm{MHz}$ transducer were employed. A complete $M$-mode echocardiographic examination showed the right ventricular dimensions and the type of the interventricular septal motion (normal, flat, or paradoxical). The two dimensional apical four-chamber view ${ }^{6}$ was used to assess the negative contrast echo effect in the right atrium, defined as a contrast-free space along the right side of the interatrial septum and within the right atrium. This was semiquantitatively graded according to the following criteria: absent $(-)$, questionable $(+-)$, weak $(+)$ when a small area of the negative contrast echo effect was present near the right side of the interatrial sep- tum, and strong $(++)$ when a large area of the right atrium was involved in the negative contrast echo $c$. effect.

The two dimensional subcostal transverse view ${ }^{16} \stackrel{0}{\stackrel{5}{\circ}}$ was obtained by directing the ultrasonic plane towards the back between the inferior vena cava and pulmonary artery through the right and left atrium and the interatrial septum. This view was used to test $\triangle$ the degree of opacification and the direction of con- $\%$ trast echoes entering, or absent from, the inferior $\vec{O}$ vena cava. M-mode echograms of the inferior vena cava were obtained by selecting the single ultrasonic beam from this view and were recorded at a paper speed of 50 or $25 \mathrm{~mm} / \mathrm{s}$.

The contrast echo effect was accepted and evaluated when it appeared only in the right atrium or in both the right atrium and the inferior vena cava. In the latter case attention was directed to detecting a 0 real penetration of echoes in the inferior vena cava $\frac{}{5}$ during presystole, that is before the $Q$ wave of the $\vec{z}$ electrocardiogram on the $M$-mode echograms. The presystolic contrast echo effect, evaluated on two consecutive inferior vena cava $M$-mode contrast echo- $\mathscr{\emptyset}$ grams, was graded according to the following criteria: ? weak $(+)$ when the contrast echo effect was of low intensity as compared with the intensity of echoes of the other structures and the amount of contrast echo $\bar{\partial}$ lines, and persisted for one to two cardiac cycles; strong $(++)$ when the contrast echo effect was of $\stackrel{\mathbb{Q}}{\mathscr{Q}}$ medium intensity and persisted for three to five car- $\overrightarrow{\vec{A}}$ diac cycles; massive $(+++)$ when the contrast echo 9 effect was of high intensity and persisted for more $\vec{T}$ than five cardiac cycles. These contrast echocardiographic tracings were read blindly and separately by two of us before cardiac catheterisation and, therefore, before the size of the shunt in the patients with? atrial septal defect was known.

DATA ANALYSIS

Statistical analysis was performed using the $t$ test. The sensitivity, specificity, and predictive accuracy of the 9 presystolic contrast echo effect in the inferior vena $\frac{7}{0}$ cava to diagnose atrial septal defect were calculated as follows:

True positives $(\mathrm{TP})=$ patients with atrial septal defect and presystolic contrast echo effect in the inferior vena cava.

False negatives $(\mathrm{FN})=$ patients with atrial septal defect and no presystolic contrast echo effect in the

inferior vena cava.
True negatives $(\mathrm{TN})=$ patients without atrial septal $\stackrel{\mathbb{D}^{+}}{+}$ defect and no presystolic contrast echo effect in the $\frac{T}{0}$ inferior vena cava.

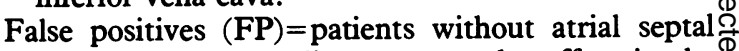

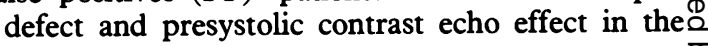
inferior vena cava. 
Sensitivity $=\frac{T P}{T P+F N} \quad$ Specificity $=\frac{T N}{T N+F P}$ Predictive accuracy $=\frac{\mathrm{TP}}{\mathrm{TP}+\mathrm{FP}}$

\section{Results}

Cardiac catheterisation confirmed the echo diagnosis in all the patients with raised right atrial and ventricu- lar pressures (range 10 to $28 \mathrm{mmHg}$ ) and in 37 patients with two dimensional echo evidence of atrial septal defect. In two patients the latter was a sinus venosus defect and in 35 an ostium secundum defect. The shunt size varied from small to large (range $11 \%$ to $88 \%$; $Q p / Q s=1.12$ to 8.4 ) (Table) and was left-toright in all. None of the patients with atrial septal defect had either pulmonary hypertension or raised right atrial and ventricular pressures (Table).

Conventional $\mathrm{M}$-mode echocardiography showed

Table Haemodynamic, echo, and contrast echocardiographic findings in 37 patients with atrial septal defect

\begin{tabular}{|c|c|c|c|c|c|c|c|c|c|c|c|}
\hline \multicolumn{8}{|c|}{ Catheterisation } & \multicolumn{2}{|l|}{ Echo } & \multicolumn{2}{|c|}{ Contrast echo } \\
\hline \multirow{2}{*}{$\begin{array}{l}\text { Age } \\
(y)\end{array}$} & \multirow[t]{2}{*}{$Q p / Q s$} & \multirow{2}{*}{$\begin{array}{l}L-R \\
\text { shunt }\end{array}$} & \multicolumn{2}{|c|}{$L A-R A$} & \multirow[t]{2}{*}{$R V E D P$} & \multirow{2}{*}{$\begin{array}{l}P A P \\
S / D / M\end{array}$} & \multirow[t]{2}{*}{$P V R I$} & \multirow[t]{2}{*}{$R V D$} & \multirow[t]{2}{*}{$I V S$} & \multirow[t]{2}{*}{$F C V-N C$} & \multirow[t]{2}{*}{$I V C-C E$} \\
\hline & & & $a$ & $m$ & & & & & & & \\
\hline $\begin{array}{r}14 \\
36 \\
10 \\
9 \\
17 \\
7 \\
23 \\
54 \\
17 \\
23 \\
34 \\
40 \\
48 \\
49 \\
17 \\
49 \\
17 \\
33 \\
28 \\
20 \\
14 \\
45 \\
29 \\
34 \\
16 \\
18 \\
36 \\
47 \\
24 \\
37 \\
27 \\
7 \\
15 \\
50 \\
24 \\
32 \\
47\end{array}$ & $\begin{array}{l}1.12 \\
1.2 \\
1.18 \\
1.37 \\
1.41 \\
1.51 \\
1.56 \\
1.59 \\
1.73 \\
2.15 \\
2.16 \\
2.21 \\
2.33 \\
2.42 \\
2.7 \\
2.9 \\
3 \\
3.1 \\
3.1 \\
3.14 \\
3.18 \\
3.37 \\
3.33 \\
3.36 \\
3.45 \\
3.5 \\
3.66 \\
4.25 \\
4.44 \\
4.5 \\
4.67 \\
4.72 \\
4.8 \\
5 \\
5.33 \\
7.86 \\
8.4\end{array}$ & $\begin{array}{l}11 \% \\
13 \% \\
15 \% \\
20 \% \\
25 \% \\
28 \% \\
30 \% \\
33 \% \\
42 \% \\
53 \% \\
53 \% \\
55 \% \\
57 \% \\
59 \% \\
63 \% \\
66 \% \\
67 \% \\
68 \% \\
68 \% \\
68 \% \\
69 \% \\
69 \% \\
70 \% \\
70 \% \\
71 \% \\
71 \% \\
73 \% \\
76 \% \\
77 \% \\
77 \% \\
77 \% \\
78 \% \\
78 \% \\
80 \% \\
81 \% \\
86 \% \\
88 \%\end{array}$ & $\begin{array}{l}4 \\
1 \\
2 \\
1 \\
2 \\
2 \\
3 \\
4 \\
3 \\
3 \\
4 \\
3 \\
4 \\
3 \\
2 \\
4 \\
1 \\
3 \\
1 \\
2 \\
2 \\
2 \\
3 \\
0 \\
2 \\
1 \\
3 \\
4 \\
2 \\
1 \\
3 \\
2 \\
1 \\
0 \\
2 \\
1 \\
2\end{array}$ & $\begin{array}{l}2 \\
1 \\
1 \\
1 \\
1 \\
2 \\
2 \\
4 \\
2 \\
3 \\
2 \\
1 \\
2 \\
1 \\
2 \\
1 \\
1 \\
2 \\
2 \\
1 \\
1 \\
2 \\
2 \\
0 \\
1 \\
2 \\
2 \\
2 \\
2 \\
1 \\
2 \\
1 \\
0 \\
0 \\
0 \\
1 \\
2\end{array}$ & $\begin{array}{l}8 \\
9 \\
7 \\
6 \\
7 \\
7 \\
7 \\
5 \\
9 \\
8 \\
7 \\
7 \\
9 \\
9 \\
8 \\
9 \\
8 \\
8 \\
8 \\
7 \\
8 \\
9 \\
8 \\
9 \\
8 \\
5 \\
8 \\
9 \\
6 \\
5 \\
9 \\
9 \\
9 \\
8 \\
8 \\
5 \\
9\end{array}$ & $\begin{array}{l}33 / 12 / 17 \\
15 / 6 / 12 \\
30 / 12 / 16 \\
35 / 11 / 18 \\
22 / 10 / 15 \\
20 / 10 / 15 \\
28 / 12 / 19 \\
32 / 10 / 18 \\
21 / 7 / 13 \\
28 / 12 / 18 \\
25 / 10 / 16 \\
23 / 7 / 12 \\
30 / 10 / 20 \\
30 / 1 / 20 \\
20 / 1 / 15 \\
33 / 17 / 20 \\
23 / 9 / 15 \\
17 / 5 / 8 \\
30 / 7 / 16 \\
26 / 9 / 18 \\
32 / 10 / 17 \\
26 / 11 / 17 \\
30 / 9 / 18 \\
30 / 12 / 18 \\
25 / 12 / 18 \\
32 / 14 / 23 \\
25 / 8 / 15 \\
32 / 13 / 18 \\
27 / 10 / 17 \\
34 / 10 / 20 \\
28 / 8 / 13 \\
30 / 12 / 17 \\
35 / 12 / 23 \\
35 / 14 / 20 \\
30 / 15 / 22 \\
20 / 6 / 11 \\
30 / 10 / 19\end{array}$ & $\begin{array}{r}67 \\
203 \\
\\
81 \\
22 \\
76 \\
205 \\
71 \\
35 \\
96 \\
44 \\
141 \\
165 \\
31 \\
169 \\
38 \\
20 \\
51 \\
41 \\
56 \\
81 \\
71 \\
78 \\
47 \\
83 \\
42 \\
123 \\
24 \\
111 \\
16 \\
36 \\
76 \\
181 \\
12 \\
41\end{array}$ & $\begin{array}{l}17 \\
20 \\
15 \\
15 \\
18 \\
18 \\
16 \\
25 \\
30 \\
40 \\
25 \\
35 \\
25 \\
35 \\
30 \\
30 \\
32 \\
30 \\
40 \\
30 \\
25 \\
50 \\
25 \\
45 \\
30 \\
45 \\
40 \\
38 \\
35 \\
35 \\
38 \\
42 \\
35 \\
40 \\
40 \\
42 \\
44\end{array}$ & $\begin{array}{l}\mathbf{N} \\
\mathbf{N} \\
\mathbf{N} \\
\mathbf{N} \\
\mathbf{N} \\
\mathbf{N} \\
\mathbf{N} \\
\mathbf{P} \\
\mathbf{N} \\
\mathbf{N} \\
\mathbf{F} \\
\mathbf{P} \\
\mathbf{N} \\
\mathbf{P} \\
\mathbf{P} \\
\mathbf{N} \\
\mathbf{N} \\
\mathbf{P} \\
\mathbf{P} \\
\mathbf{P} \\
\mathbf{P} \\
\mathbf{P} \\
\mathbf{P} \\
\mathbf{P} \\
\mathbf{N} \\
\mathbf{P} \\
\mathbf{F} \\
\mathbf{P} \\
\mathbf{P} \\
\mathbf{P} \\
\mathbf{P} \\
\mathbf{N} \\
\mathbf{F} \\
\mathbf{P} \\
\mathbf{P} \\
\mathbf{P} \\
\mathbf{P}\end{array}$ & $\begin{array}{l}- \\
- \\
- \\
- \\
- \\
- \\
- \\
+ \\
+ \\
+ \\
+ \\
+ \\
+ \\
+ \\
+ \\
+ \\
+ \\
+ \\
+ \\
+ \\
+ \\
+ \\
+ \\
+ \\
+\end{array}$ & $\begin{array}{l}+ \\
+ \\
+ \\
+ \\
+ \\
+ \\
+ \\
+ \\
++ \\
++ \\
++ \\
++ \\
++ \\
++ \\
++ \\
++ \\
++ \\
++ \\
++ \\
++ \\
++ \\
+ \\
+++ \\
++ \\
+++ \\
++ \\
++ \\
+++ \\
+++ \\
++ \\
++ \\
+++ \\
+++ \\
+++ \\
+++ \\
+++ \\
+++ \\
+++\end{array}$ \\
\hline $\begin{array}{c}8 \\
\text { pts }\end{array}$ & $\begin{array}{l}1.36 \\
\pm 0.2 \\
p<0.001\end{array}$ & $\begin{array}{l}21.8 \\
\pm 8.3 \\
p<0.001\end{array}$ & $\begin{array}{l}2 \cdot 3 \\
\pm 1 \cdot 2 \\
\mathrm{NS}\end{array}$ & $\begin{array}{l}1 \cdot 7 \\
\pm \mathrm{i} \\
\mathrm{NS}\end{array}$ & $\begin{array}{l}7 \cdot 0 \\
\pm 1 \cdot 2 \\
\mathrm{NS}\end{array}$ & & & $\begin{array}{l}18.0 \\
\pm 3.3 \\
p<0 . c\end{array}$ & & & + \\
\hline $\begin{array}{l}18 \\
\text { pts }\end{array}$ & $\begin{array}{l}2.96 \\
\pm 0.7 \\
p<0.001\end{array}$ & $\begin{array}{l}64.1 \\
\pm 9.2 \\
p<0.001\end{array}$ & $\begin{array}{l}2 \cdot 4 \\
\pm 1 \cdot 1 \\
\text { NS }\end{array}$ & $\begin{array}{l}1.6 \\
\pm 0 \cdot 6 \\
\text { NS }\end{array}$ & $\begin{array}{l}7 \cdot 6 \\
\pm 1 \cdot 3 \\
\mathrm{NS}\end{array}$ & & & $\begin{array}{l}32.1 \\
\pm 5.7 \\
\mathbf{p}<0.6\end{array}$ & & & ++ \\
\hline $\begin{array}{l}11 \\
\text { pts }\end{array}$ & $\begin{array}{l}5.03 \\
\pm 1.6\end{array}$ & $\begin{array}{l}77.8 \\
\pm 5.9\end{array}$ & $\begin{array}{l}1.8 \\
\pm 1 \cdot 3\end{array}$ & $\begin{array}{l}1 \cdot 1 \\
\pm 1\end{array}$ & $\begin{array}{l}8.3 \\
\pm 1 \cdot 2\end{array}$ & & & $\begin{array}{l}41 \cdot 2 \\
\pm 4 \cdot 1\end{array}$ & & & +++ \\
\hline
\end{tabular}

Abbreviations: $Q p / Q s$, pulmonary to systemic flow ratio; L-R, left-to-right; LA-RA, left atrial-right atrial pressure gradient (mmHg) measured at "a" wave (a) or the mean (m); RVEDP, right ventricular end-diastolic pressure (mmHg); PAP, pulmonary artery pressure (mmHg); S, systole; D diastole; $M$, mean; PVRI, pulmonary vascular resistance index (mean PAP-pulmonary wedge pressure)/cardiac index $(\mathrm{mmHg}) ; \mathrm{S}$, systole; $\mathrm{D}$, diastole; $\mathrm{M}$, mean; $\mathrm{PVR}$, pulmonary vimension in $\mathrm{mm}$; IVS, interventricular septal motion $(\mathrm{P}$, paradoxical; $\mathrm{F}$, flat; $\mathrm{N}$, normal); FCV-NC, negative contrast echo from apical four chamber view; IVC-CE, presystolic contrast echo effect in the inferior vena cava; - , absent; +-, questionable; + , weak; ++ , strong; +++ , massive; NS, not significant; pts, patients. 
the typical combination of a dilated right ventricle and abnormal interventricular septal motion in 20 of our 37 patients. Normal interventricular septal motion was recorded in 14 patients, and the combination of a normal right ventricle and normal interventricular septal motion was found in seven patients with the lowest values of shunt (Table).

\section{CONTRAST ECHOCARDIOGRAPHY}

All injections performed in an individual patient produced a similar contrast echo effect, which in the majority of cases was evaluated identically by the two observers. In five patients with atrial septal defect the findings on the apical view were considered questionable because of different interpretation of the two observers.

In none of the normal subjects were contrast echoes entering the inferior vena cava detected. In all the

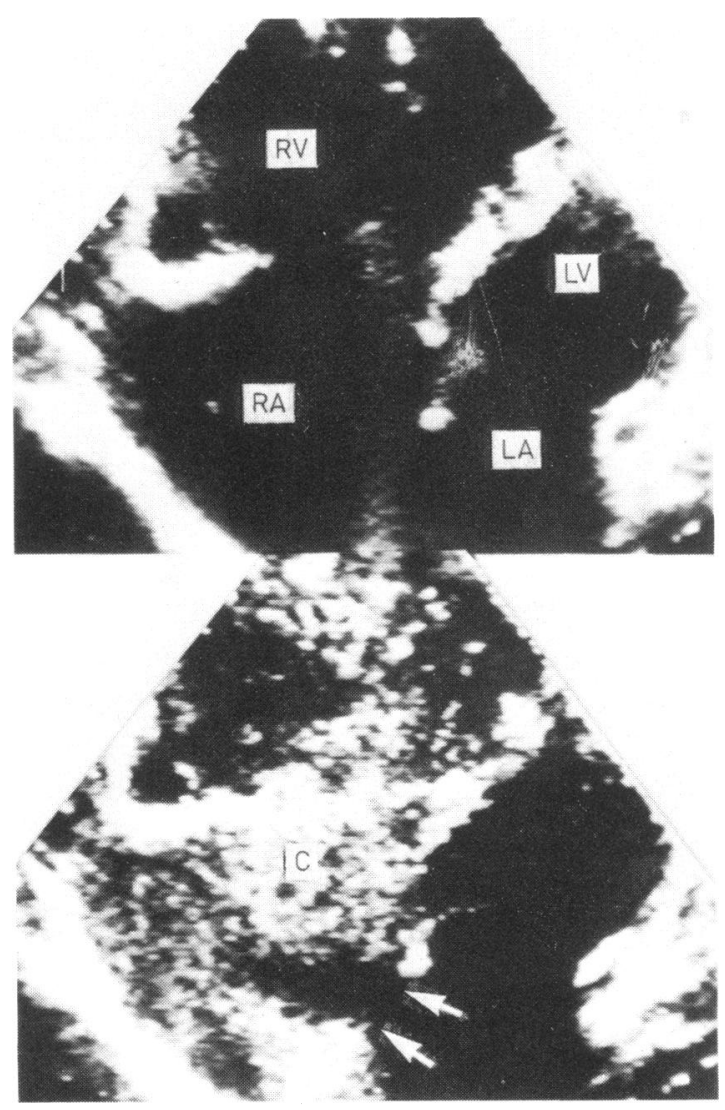

Fig. 1 Two dimensional apical four-chamber view in patient with atrial septal defect just before (top) and during (bottom) contrast echocardiography. Arrows indicate a weak negative contrast echo effect. $R A$, right atrium; $R V$, right ventricle; $L A$, left atrium; $L V$, left ventricle; $C$, contrast echoes. patients and normal subjects, however, a satisfactory opacification of the right atrium and ventricle was obtained.

From the apical approach a negative contrast echo effect in the right atrium of the patients with atrial septal defect was absent in 10 , questionable in five, weak in 14, and strong in eight (Table; Fig. 1). No correlation was found between the graded negative contrast echo effect and the size of the shunt (Table).

In all patients with atrial septal defect and in 10 patients with a raised right ventricular pressure, from the subcostal transverse view, a to-and-fro motion of contrast echoes between the right atrium and the inferior vena cava with a direction perpendicular to the incidence of the ultrasonic place was found (Fig. 2). In these patients contrast echoes were seen entering the inferior vena cava during early diastole and/or presystole, that is after the $\mathrm{T}$ wave and/or before the $Q$ wave of the electrocardiogram, as seen in the $\mathrm{M}$-mode tracings (Fig. 3A, B, C). In some of the patients presystolic or early diastolic contrast echoes were detected which were synchronous with the " $a$ " wave or after the " $v$ " wave of either the inferior vena cava echocardiogram or the jugular pulse, when it was able to be recorded (Fig. 4). The sensitivity, specificity, and predictive accuracy of the presystolic contrast echo effect in the inferior vena cava for diagnosing atrial septal defect with left-to-right shunt were $100 \%, 50 \%$, and $77 \%$, respectively. In all the patients with a raised right ventricular pressure the $M$-mode and/or two dimensional conventional echocardiographic examinations were sufficient to establish the main cardiac diagram. When these patients were excluded, the specificity and predictive accuracy of the presystolic contrast pattern in diagnosing atrial septal defect were $100 \%$ for both.

In eight patients with congestive cardiomyopathy or pericardial effusion with the lowest values of right ventricular pressure, false penetration of contrast echoes in the inferior vena cava was identified if echoes appeared to have a to-and-fro motion towards the transducer, if they were identified outside the $\frac{7}{0}$ inferior vena cava and, finally, if they disappeared when the single beam for the M-mode echo of the $N$ inferior vena cava was selected further from the right $N$ atrium, or when the transducer was angulated towards the inferior vena cava (Fig. 5).

Using the same procedure for all patients with atrial septal defect, the same opacification of the right $\stackrel{\circ}{C}$ atrium was obtained in all, though different degrees of opacification of the inferior vena cava were observed. In these patients the graded contrast echo effect in the inferior vena cava was weak in eight, strong in 18, and $\vec{D}$ massive in 11 (Table). At catheterisation the values of $\frac{\widetilde{Q}}{\mathbb{\Phi}}$ the oximetric shunt were found to be directly related $\odot$ to the graded contrast echo effect (Table). In 20 post-

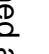
(1) $\vec{\circ}$ $\vec{\omega}$ T)

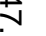
i c -

窟




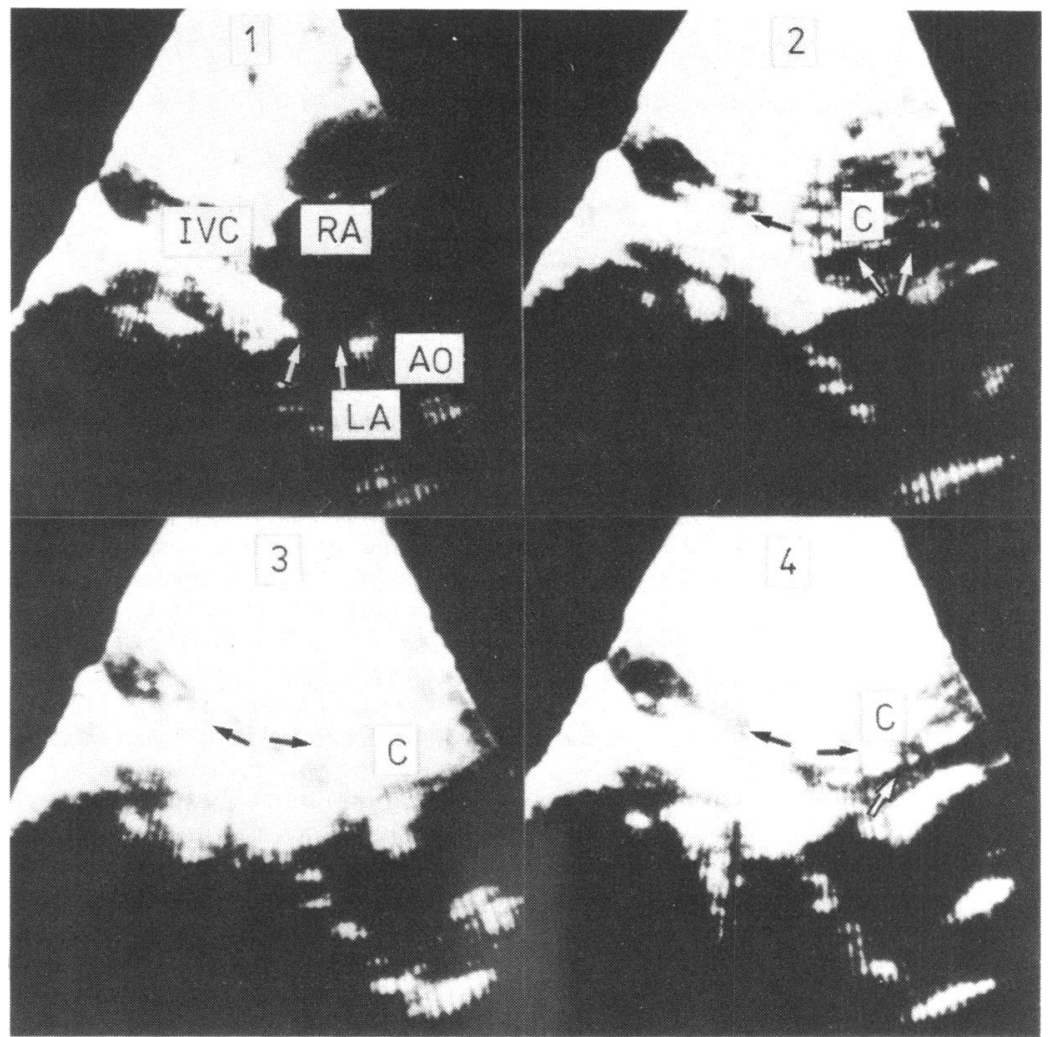

Fig. 2 Two dimensional subcostal transverse view. Subsequent frames during contrast injection in patient with atrial septal defect. Arrows in panel 1 indicate the dropout of echoes between the right $(R A)$ and left $(L A)$ atrium. Contrast echoes $(C)$ enter the inferior vena cava (IVC) from the right atrium with $a$ to-and-fro motion (black arrows) perpendicular to the incidence of the ultrasonic plane. White arrows indicate non-contrast-containing blood coming from the left atrium.

operative patients no contrast echoes were found to enter the inferior vena cava during presystole and the opacification of the right atrium and ventricle was normal. The absence of presystolic contrast echoes in the inferior vena cava after surgery is well documented in Fig. 6. In this case, contrast 1 (presystole) and contrast 2 (late systole) in panel A were attributed to an atrial septal defect and tricuspid regurgitation caused by tricuspid valve prolapse, respectively, as shown by cardiac catheterisation. After surgical correction of the septal defect no contrast echoes were detected in the inferior vena cava during presystole, whereas only contrast 2 was present (arrows in panel B) and attributed to the persistence of tricuspid regurgitation.

\section{Discussion}

M-mode echocardiograms are not specific and sensitive enough to prove the presence of atrial septal defect with left-to-right shunt. ${ }^{1-3}$ In fact, these findings may be absent in patients with small atrial septal defects and small left-to-right shunts, and it is more frequent to record a normal $\mathrm{M}$-mode echocardiogram or a normal interventricular septal motion even when the shunt is large ${ }^{5}$ (Table). Using two dimensional contrast echocardiography some authors $^{11-13}$ noticed a negative contrast echo effect in the right atrium, that is a contrast-free space along the right side of the interatrial septum caused by the non-contrast-containing blood passing from left to right across the defect (Fig. 1). This effect is enhanced during the Valsalva manoeuvre, ${ }^{11}$ but not in all patients with atrial defect and left-to-right shunt was it detected clearly (Table). The reliability of this technique in diagnosing the defect depends upon many factors, such as poor sound transmission characteristics, too few contrast echoes, ${ }^{13}$ and the position of the transducer.

We have previously observed presystolic contrast echoes entering the inferior vena cava in patients with atrial septal defect and a dominant left-to-right shunt, and attributed the contrast echo feature to the flow directed from left to right and towards the inferior vena cava. ${ }^{16}$

In the present investigation this pattern had a sensitivity of $100 \%$ but a low specificity and predictive accuracy in diagnosing atrial defect. This is because other conditions determining raised right atrial and ventricular pressure appeared to have a presystolic 


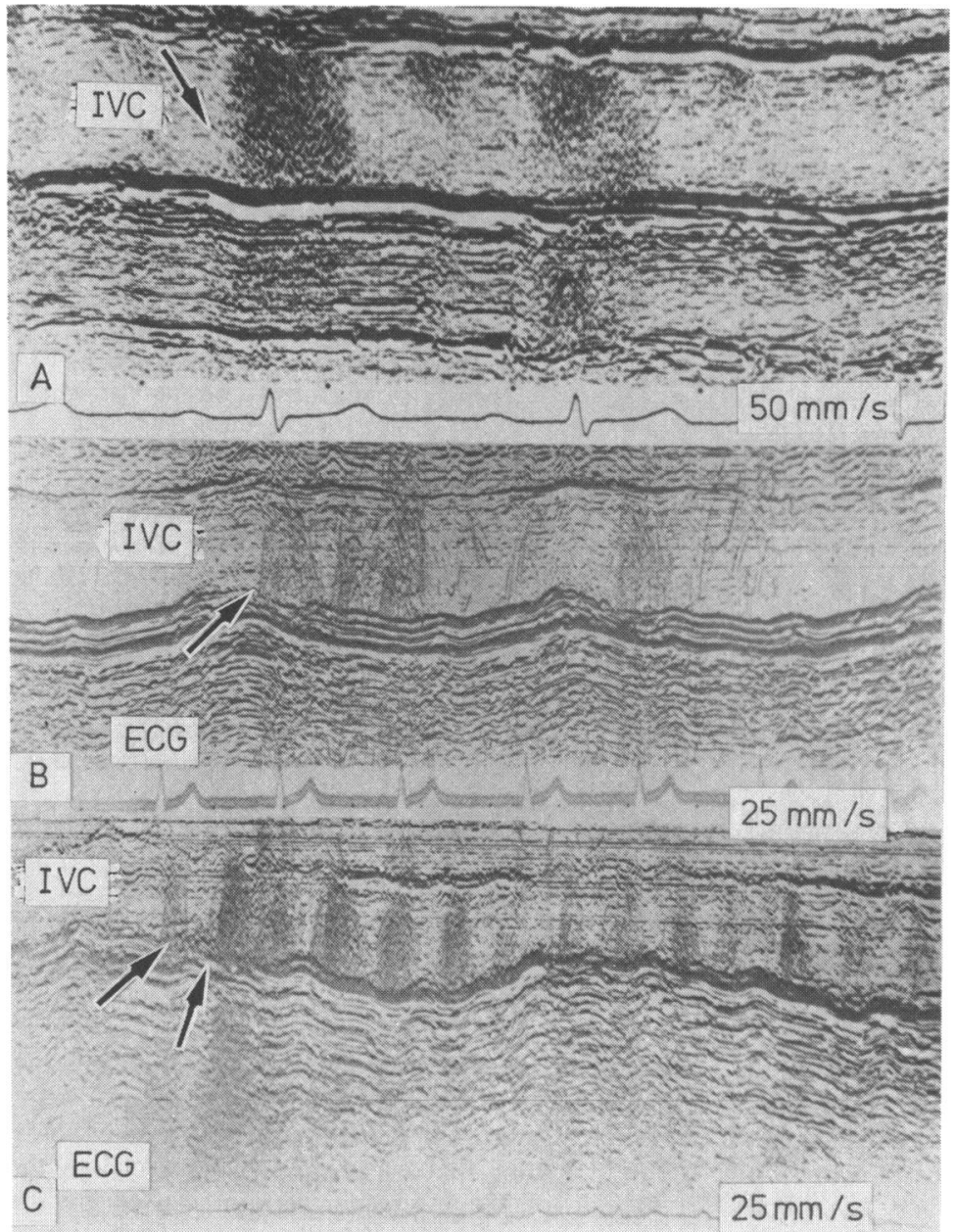

Fig. $3 M$-mode inferior vena cava (IVC) contrast echocardiograms in atrial septal defect and left-to-right $(L-R)$ shunt. Panel $A$, patient with small $L-R$ shunt. Arrow indicates the presystolic appearance of contrast echoes persisting for two cardiac cycles. Notice the absence of contrast during the third beat. Panel $B$, patient with $L-R$ shunt of medium size. Arrow indicates the presystolic appearance of contrast lines persisting for four cardiac cycles. Panel $C$, patient with large $L-R$ shunt. Arrows indicate the diastolic appearance of contrast echoes persisting for more than five cardiac cycles.

contrast echo effect. When these were excluded by the initial M-mode and two dimensional echo scan the specificity and predictive accuracy increased significantly and the presence of the defect was proved in $100 \%$ of the cases. Other conditions that could affect this echo pattern include the cardiac rhythm, inspiration, and false entry of contrast echoes in the inferior vena cava. The timing of appearance of contrast echoes must first be identified. This is easy when contrast echoes appear during presystole, that is just before the $Q$ wave of the electrocardiogram. The diastolic appearance is sometimes difficult to define, especially when the $T$ wave of the electrocardiogram is not clearly inscribed. In both cases, however, the " $a$ " and " $v$ " waves of either the inferior vena cava or the jugular pulse may help to define clearly the timing of the appearance of contrast ${ }^{17}$ (Fig. 4). As previously reported, neither atrial fibrillation nor inspiration modify the time relation between the cardiac cycle $\delta$ and the entry of contrast echoes into the inferior vena cava. ${ }^{16} 18$ In the present series, however, all patients 음 with atrial septal defect presented with sinus rhythm, $\rightarrow$ and no difference was observed in the results during either regular breathing or held respiration. Further- $N$ more, if the transducer is abnormally positioned it ${ }^{\circ}$ may be possible to detect contrast echoes recirculating $N$ into the right atrium, superimposed on the inferior $\omega$ vena cava, and erroneously localised inside it. This false entry may be identified by altering the angle of 0 the transducer and reviewing the two dimensional $\mathbb{D}$ recordings in slow motion or frame by frame (Fig. 5). ?

On the other hand, despite all these limitations, the 0 reliability of the presystolic contrast echo effect in the inferior vena cava for the diagnosis of atrial septal defect with left-to-right shunt is also supported in this $\frac{\mathbb{Q}}{2}$ study by the fact that this effect is absent in patients 


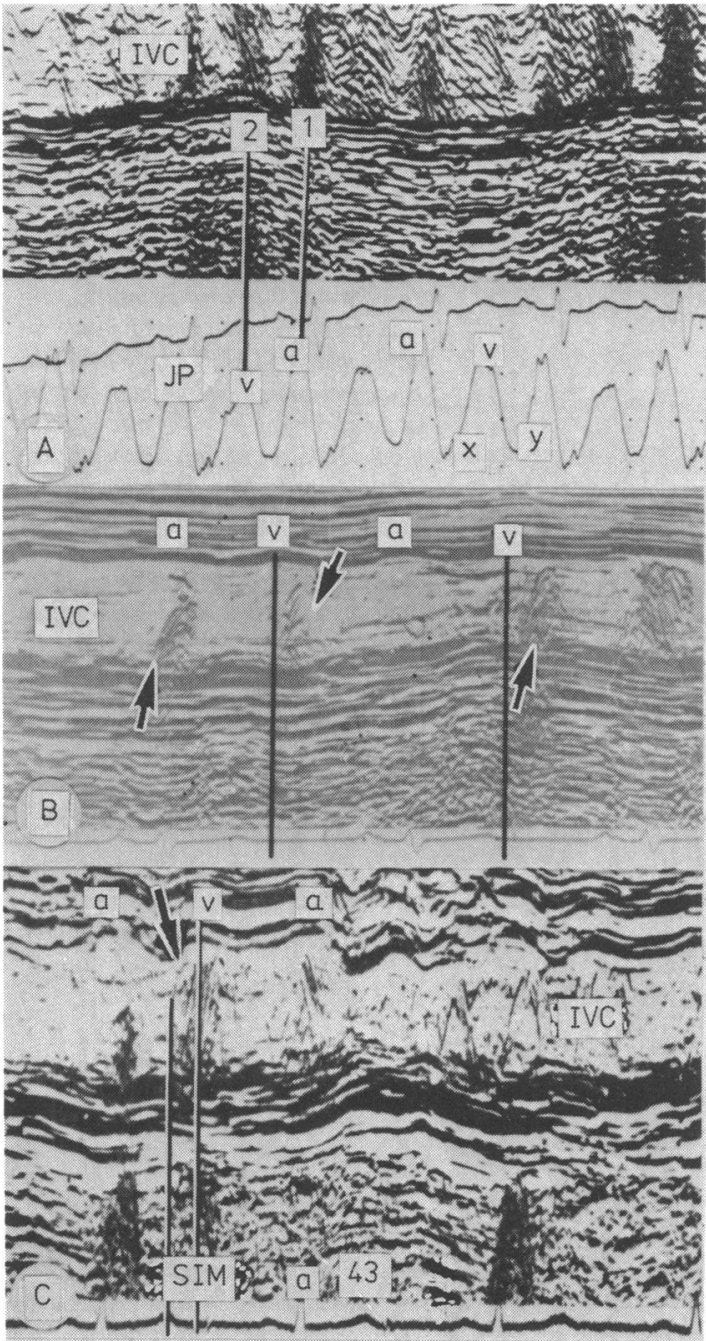

Fig. 4 Contrast $M$-mode echograms of the inferior vena cava (IVC). Panel A, patient with tricuspid regurgitation and atrial septal defect. Presystolic (1) and systolic (2) contrast echoes are synchronous with the " $a$ " and " $v$ " waves of the jugular pulse $(\mathcal{P})$, respectively. Panel $B$, patient with atrial septal defect. Contrast lines enter the inferior vena cava after both the $T$ wave of the electrocardiogram and peak " $v$ " wave of the inferior vena cava (second and third arrow). The first arrow indicates presystolic contrast lines synchronous with the " $a$ " wave. Panel $C$, patient with tricuspid regurgitation and pulmonary hypertension caused by severe mitral stenosis. Contrast lines (arrow) are synchronous with the peak " $v$ " wave of the inferior vena cava. Contrast synchronous with the " $a$ " wave is also visible.

after operation (Fig. 6). In order to test any possible relation between the oximetric size of the shunt and the graded appearance of contrast echoes in the inferior vena cava we divided the patients into three groups according to whether they presented a weak, strong, or massive contrast echo effect. These groups bore a significant relation to the size of shunt but not to the mean left-to-right atrial pressure gradient or the right ventricular pressure (Table).

It is possible that this effect is the result of the flow directed from left to right towards the inferior vena cava, during diastole and, particularly, during presystole when the contraction of both atria occurs. ${ }^{16}$ This is in agreement with Doppler echo studies on patients with atrial septal defect previously reported.19-21 Moreover, since the patients with low shunts on oximetry had weak contrast echo effects, whereas those with high shunts showed massive ones, it is inferred that the graded appearance of contrast echoes in the inferior vena cava be related to the left-to-right oximetric shunt and, therefore, to the amount of flow. The ability of the techinque to grade and anticipate the size of the shunt, even if semiquantitatively, may depend upon many factors such as the force of injection, the velocity of blood flow, and respiratory events, which may modify the intensity and the amount of contrast echoes. ${ }^{16}$ In the present study, however, all patients either breathed normally or held their breath, all injections were performed by the same operator, and in individual patients contrast echo effects were seen to be reproducible. In conclusion, the presystolic appearance of contrast echoes in the inferior vena cava is a reliable and useful method of proving the presence of atrial septal defect with left-to-right shunt, particularly in those patients suspected of having the defect but with normal findings on conventional echocardiography.

We are grateful to Drs N R Lundstrom, Lund, Sweden, and Daniel R Pieroni, Buffalo, New York, for their advice and criticism in preparing the manuscript.

\section{References}

1 Diamond MA, Dillon JC, Haine CL, Chang S, Feigenbaum H. Echocardiographic features of atrial septal defect. Circulation 1971; 43: 129-35.

2 Meyer RA, Schwartz DC, Benzing G, III, Kaplan S. Ventricular septum in right ventricular volume overload; an echocardiographic study. Am $\mathcal{F}$ Cardiol 1972; 30: 349-53.

3 Tajik AJ, Gau GT, Ritter DG, Schattenberg TT Echocardiographic pattern of right ventricular diastolic volume overload in children. Circulation 1972; 46: 36-43.

4 Dillon JC, Weyman AE, Feigenbaum H, Eggleton RC, Johnston K. Cross sectional echocardiographic examination of the interatrial septum. Circulation 1977; 5: 115 20.

5 Lieppe W, Scallion R, Behar VS, Kisslo JA. Two- 

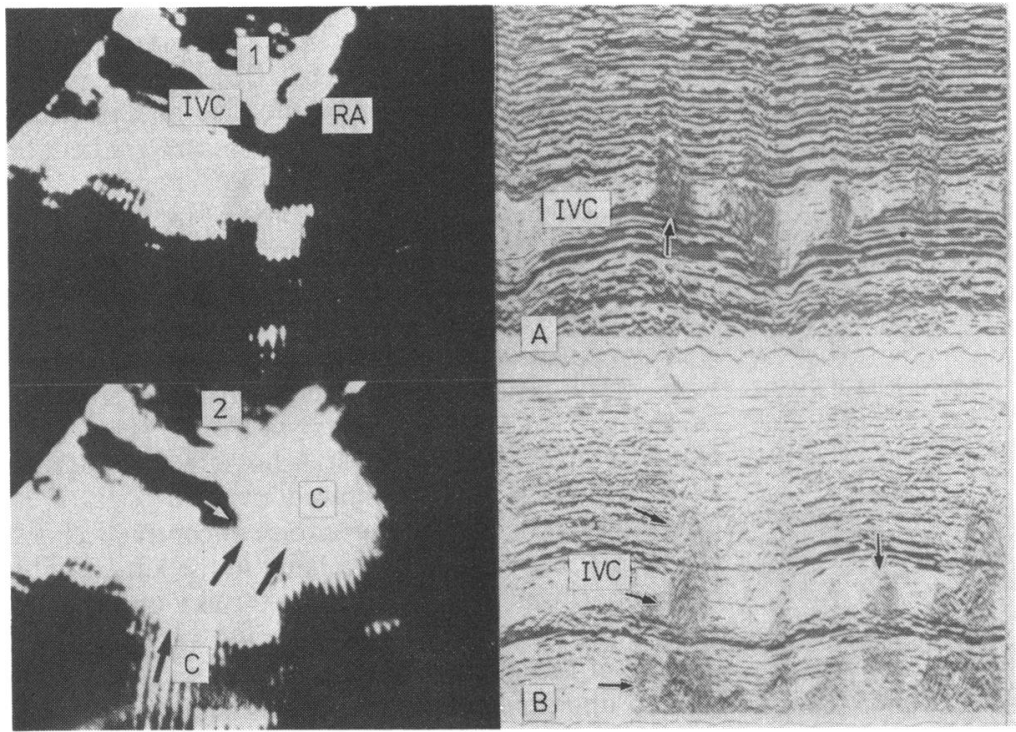

Fig. 5 On the left, sequential frames of two dimensional contrast echocardiogram in a case of false entry of contrast echoes $(C)$ in the inferior vena cava (IVC). Contrast echoes are identified near the entry of the inferior vena cava, outside it and within the right atrium $(R A)$ at the same time, with a to-and-fro motion towards the transducer (black arrows) and superimposed on the inferior vena cava (compared with Fig. 2). White arrow indicates blood without contrast material coming from the inferior vena cava. On the right, inferior vena cava (IVC) contrast M-mode echogram. Panel A, true entry (patient with atrial septal defect) of contrast echoes in the inferior vena cava, when the single beam was selected further from the right atrium. Arrow indicates presystolic contrast lines in the inferior vena cava. Panel $B$, false entry of contrast echoes in the inferior vena cava. Arrows indicate contrast echoes superimposed on the inferior vena cava and outside of it. In this case no contrast echoes were detected inside the inferior vena cava when the beam was

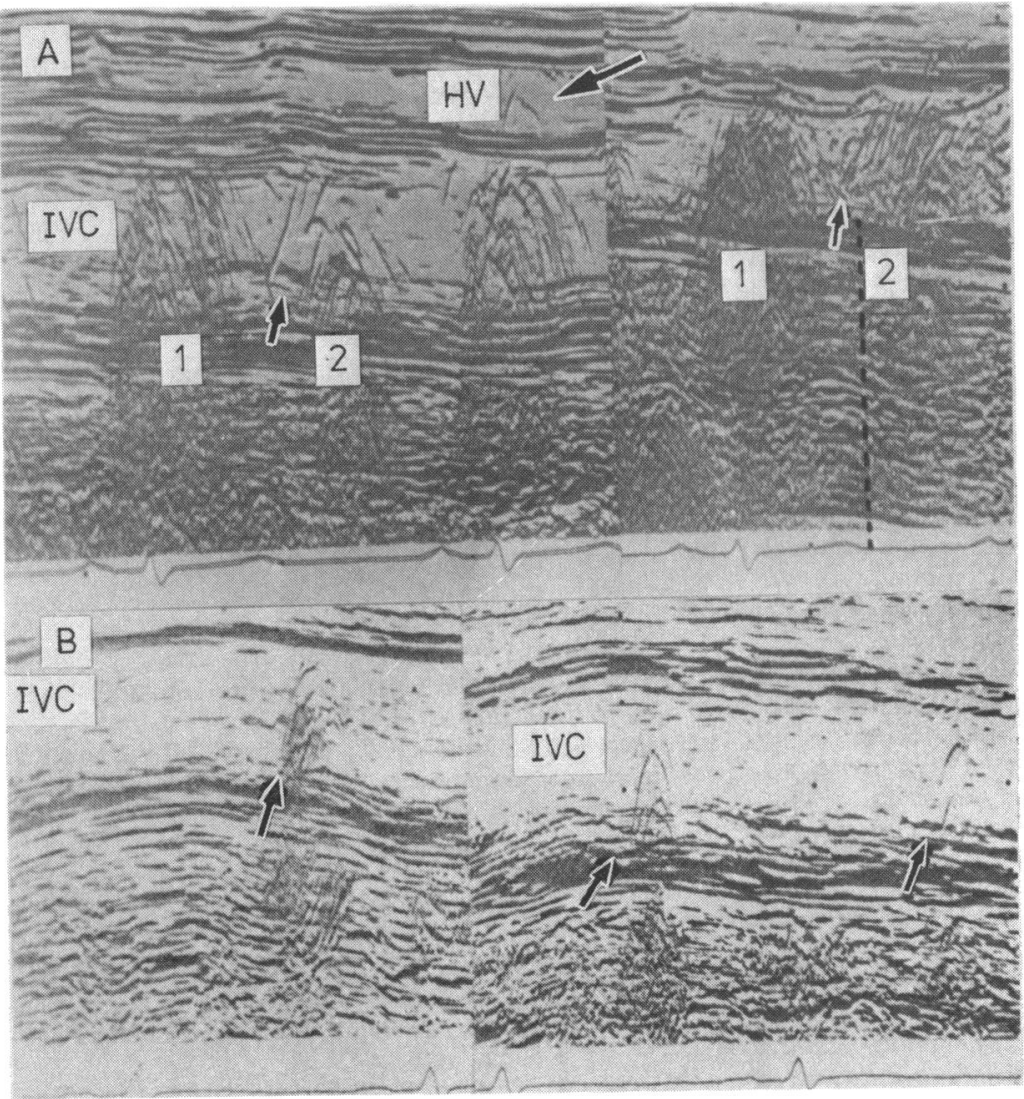
selected further from the right atrium.

Fig. 6 M-mode contrast echogram of the inferior vena cava in case of tricuspid regurgitation caused by late systolic prolapse and atrial septal defect. Panel A, contrast echoes enter the inferior vena cava during presystole (1) and late systole (arrows in 2). Upper arrow indicates contrast lines in the hepatic vein (HV). Panel $B$, same patient after surgical correction of the septal defect. No presystolic echoes are seen. Arrows indicate the persistence of contrast echo lines 2 seen in panel $A$. 
dimensional echocardiographic findings in atrial septal defect. Circulation 1977; 56: 447-56.

6 Silverman NH, Schiller NB. Apex echocardiography: a two-dimensional technique for evaluating congenital heart disease. Circulation 1978; 57: 503-11.

7 Bierman FZ, Williams RG. Subxiphoid two-dimensional imaging of the interatrial septum in infants and neonates with congenital heart disease. Circulation 1979; 60: 80 90.

8 Lange LW, Sahn, DJ, Allen HD, Goldberg SJ. Subxiphoid cross-sectional echocardiography in infants and children with congenital heart disease. Circulation 1979; 59: 513-24.

9 Valdez-Cruz LM, Pieroni DR, Roland JMA, Varghese PJ. Echocardiographic detection of intra-cardiac rightto-left shunts following peripheral vein injections. Circulation 1976; 54: 558-62.

10 VAldez-Cruz LM, Pieroni DR, Roland JMA, Shematek JP. Recognition of residual postoperative shunts by contrast echocardiographic techniques. Circulation 1977; 55: 148-52.

11 Kronik G, Slany J, Moesslacher H. Contrast M-mode echocardiography in diagnosis of atrial septal defect in acyanotic patients. Circulation 1979; 59: 372-8.

12 Weyman AE, Wann LS, Caldwell RL, Hurwitz RA, Dillon JC, Feigenbaum H. Negative contrast echocardiography: a new method for detecting left-to-right shunts. Circulation 1979; 59: 498-505.

13 Fraker TD Jr, Harris PJ, Behar VS, Kisslo JA. Detection and exclusion of interatrial shunts by twodimensional echocardiography and peripheral venous injection. Circulation 1979; 59: 379-84.

14 Gullace G, Savoia M, Locatelli V, Rusconi F. L'ecocontrastografia della vena cava inferiore (abstract) $G$ Ital Cardiol 1980: 10, suppl I: 101.
15 Gullace G, Savoia M, Locatelli V, Ranzi C. Evaluation of contrast echo effect in inferior vena cava and pulmonary valve. In: 4th European congress on ultra sonics in medicine. (International Congress Series No 547.) Amsterdam: Excerpta Medica, 1981: 66.

16 Gullace G, Saoia M, Locatelli V, Ravizza P, Ranzi C. Contrast echocardiography of the inferior vena cava. $G$ Ital Cardiol (in press).

17 Meltzer RS, van Hoogenhuyze D, Serruys PW, Haalebos MMP, Hugenholtz PG, Roelandt J. Diagnosis of tricuspid regurgitation by contrast echocardiography. Circulation 1981; 63: 1093-9.

18 Wise NK, Myers S, Fraker TD, Stewart JA, Kisslo JA. Contrast $M$-mode ultrasonography of the inferior vena cava. Circulation 1981; 63: 1100-3.

19 Kalmanson D, Veyrat C, Cholot N, Berkman M, Malergue $\mathrm{Ch}$. Recording of shunt flow patterns of atrial and ventricular septal defects and of tricuspid regurgitation using non-invasive echo-Doppler velocimetry (abstract). 2nd Meeting of WFUMB, Miyazaki, Japan 1979; 75.

20 Sakakibara H, Miyatake K, Kinoshita N, Beppu S, Nimura Y. Detection of shunt flow in atrial septal defect with a combined use of the ultrasonic pulsed Doppler technique and cross-sectional echocardiography (abstract). 2nd Meeting of WFUMB, Miyazaki, Japan 1979; 76.

21 Matsuo S, Oku Y, Utsunomiya T, Inoue J, Tsuruta $M$, Hashiba K. Superior vena cava flow velocity in man measured with the bidirectional Doppler flowmeter catheter (abstract). 2nd Meeting of WFUMB, Miyazaki, Japan 1979; 144.

Requests for reprints to Dr Giuseppe Gullace, Via Dante 14, 22054 Mandello del Lario (CO), Italy. 